\title{
Trabalhar: usar de si - sair de si
}

\author{
Maria Elizabeth Barros de Barros ${ }^{1}$
}

O artigo em debate lança questões que inquietam, provocam, forçam-nos a pensar. Cecílio formula questões, e não interrogações-opiniões. Deleuze (2006) dizia que não suportava discussões pautadas em interrogações, pois não há razão para discutir algo, se ninguém sabe de que problema se trata. Assim, formular um problema é questionar uma "imagem dogmática do pensamento" (Deleuze, 2000, p.229), interrogar os lugares comuns, e fazer liberar a vida, não a deixando minguar. Como fazer a vida não minguar no curso de projetos pautados em perspectivas de gestão em saúde que, conforme Cecílio, são construídos seguindo princípios funcionalistas, nos quais o trabalhador fica reduzido às funções que exerce na organização? Ou, ainda, como fazer a vida não minguar, quando esses projetos partem da existência de trabalhadores "desistorizados", desterritorializados, que orientariam suas práticas de forma automática, segundo as diretrizes definidas pelos dirigentes da organização?

Cecílio nos adverte sobre dois cuidados a serem tomados na gestão em saúde: o primeiro refere-se aos desvios funcionalistas e o segundo à existência do que chama trabalhador moral, porque "moralmente comprometido" com projetos considerados justos e necessários ao processo de construção do SUS. Segundo o autor, o trabalhador funcional/moral expressa a pretensão de expropriar "a margem de liberdade" dos humanos e de impor-lhes uma racionalidade única nos modos de se organizar o cuidado e de se fazer a gestão - mesmo quando formulados por militantes/intelectuais/gestores engajados na reforma sanitária - subestimando seu protagonismo e sua força instituinte, como se isso fosse possível.

Então, diante desses riscos, Cecílio nos questiona: o que colocar no lugar e evitar "[...] uma posição de relativismo ou de um laissez faire inconseqüente"? Como "[...] operar uma revolução copernicana [...]" nos modos de gestão em saúde? Podemos resistir aos projetos que funcionam como modelos que adquirem estatuto e força de prática modelizadora e incidem nos corpos dos trabalhadores lá onde se alojam seus afetos, suas emoções e toda a sua história, efetuando regulações que estão sempre tentando engoli-los? Cecílio apresenta um tema que nos desafia. Desafia-nos a colocar em análise o modo de produção no contemporâneo, marcado pela precarização das relações de trabalho e pelos fracos vínculos que os trabalhadores estabelecem nos e com os seus espaços/processos de trabalho (Barros \& Benevides de Barros, 2007). Desafia-nos a construir modos de trabalhar que afirmem o caráter inventivo dos trabalhadores, sua potência instituinte.

\footnotetext{
* O título parte das expressões utilizadas por Yves Schwartz (2003), na abordagem ergológica, e por Yves Clot (2006), na clínica da atividade, respectivamente, que serão apresentadas ao longo do texto.

${ }^{1}$ Psicóloga; pós-doutora em Saúde Pública; professora, departamento de Psicologia e Programas de Pós-Graduação em Educação $e$ em Psicologia Institucional; departamento de Psicologia, Centro de Estudos Gerais, Universidade Federal do Espírito Santo. Vitória, ES. <betebarros@uol.com.br>
} 
Encontramos hoje uma rica literatura, em especial na Abordagem Ergológica de Yves Schwartz (2003) e na Clínica da Atividade de Yves Clot (2006), que pode nos ajudar na construção deste projeto de resistir à produção dessa forma trabalhador funcional/moral. A tese fundamental desses dois autores é a de que o vital do humano não se resigna às condições dadas de trabalho. Para Schwartz (2003), a atividade humana não pode ser considerada uma seqüência de atos rigorosamente determinada. Quaisquer que sejam as circunstâncias, há sempre a negociar uma eficácia para as operações que devem gerar dimensões de historicidade nas situações de trabalho. "Não se governa o uso industrioso de homens e mulheres" (Schwartz, 2003, p.34). Toda situação de trabalho é lugar de uma "dramática" subjetiva onde se negociam circunstâncias pessoais, históricas, entre usos de si pelos outros e usos de si por si mesmo que se cruzam, constituindo uma "dramática", um destino a ser vivido. Assim, os humanos têm de fazer escolhas para fazer valer suas próprias normas de vida, produzindo formas de "des-anonimar" o meio. Não há atividade humana desenvolvida mecanicamente, como postulava a organização científica do trabalho.

Yves Clot (2006), lendo Wallon, afirma que Taylor teria exigido pouco dos trabalhadores, na medida em que teria amputado o trabalhador de sua iniciativa, o que acaba por desembocar num esforço dissociativo, fatigante e extenuante, um esforço que não se reduz ao que o homem faz para seguir a cadência do trabalho, mas inclui, igualmente, aquele com quem ele deve consentir para reprimir sua própria atividade. " $A$ calibração dos gestos é uma amputação do movimento" (Wallon apud Clot, 2006, p.14). O trabalho é, então, a capacidade de estabelecer engajamentos e pode perder o sentido quando não permite a realização das metas vitais e dos valores que o sujeito extrai dos diferentes domínios da vida em que está envolvido, pois o trabalho é, também, um meio de "[...] invenção dessas vidas" (Clot, 2006, p.14). Logo, se não pudermos pressupor esta atividade de recentramento, se considerarmos que trabalhar é pura execução, mesmo se, por vezes, massivamente contrariada, estaremos negando o que é essencial do vital humano. Por outro lado, não podemos negligenciar que as prescrições são importantes para não cairmos numa "posição de relativismo ou de um laissez faire inconseqüente", preocupação expressa por Cecílio, pois uma situação pode ser perturbada na ausência de uma organização prévia, estabilizada e partilhada da ação. A formalização, ao combinar regras escritas e não escritas, faz-se necessária para que os que trabalham não sejam deixados a si mesmos numa situação em que eles se degradem (Clot, 2006). Precisamos do prescrito, pois a organização é necessária para toda atividade humana; não precisamos é de nos engessar no que está prescrito de forma que a realização do trabalho seja perturbada ou impedida. Temos, então, uma situação paradoxal.

Mas devemos insistir um pouco mais no desafio a que o autor nos convoca e perguntar: como resistir a essa forma trabalhador funcional/moral? Arriscamos, aqui, a formulação de um outro conceito, a do trabalhador ético², que toma decisões que nos levam a um outro modo de existir, operador da nossa existência, selecionando o que favorece e o que não favorece a vida e tendo como critério a afirmação de sua potência criadora. A nosso ver, para construir uma prática de gestão que supere funções administrativas que buscam o permanente controle do autogoverno dos trabalhadores, é necessário que se faça uma ampliação da gestão dos processos de trabalho. É nesse sentido que Barros e Benevides de Barros (2007) afirmam a importância dessa ampliação, o que implica mudança no modo como operamos os processos de trabalho e que só se efetiva se partirmos dos diferentes vetores que constituem a gestão: sujeitos, saberes e poder, concebida na intercessão inseparável desses vetores e constituindo-se como um deles. Colocamos, assim, a gestão como aquilo que não pode ser substancializado, "[...] que não deve se confundir com um lugar, mas como um conector, gestão como elemento-passagem entre fluxos de trabalho/saberes; fluxos de subjetivação/sujeito; fluxos de relação/poder" (Barros \& Benevides de Barros, 2007, p.64).

\author{
2 O conceito de \\ trabalhador ético que \\ estamos propondo \\ baseia-se nas \\ formulações \\ apresentadas \\ inicialmente por Rolnik \\ em 1992 sobre o homem \\ da moral e o homem da \\ ética (Rolnik, 1997). O \\ primeiro é o vetor de \\ nossa subjetividade que \\ conhece os códigos, o \\ conjunto de valores e \\ regras vigentes na \\ sociedade em que \\ estamos vivendo. $\mathrm{O}$ \\ homem da ética que nos \\ habita é o vetor que \\ escuta as inquietantes \\ reverberações das \\ diferenças que se \\ engendram em nosso \\ inconsciente.
}


Nesse sentido, a construção de políticas públicas em saúde deve estar comprometida com a coletivização da gestão, com a publicização das relações entre trabalho (saberes), sujeitos (necessidades, desejos e interesses) e poderes (modos de relacionar saberes e sujeitos). Problematizar a relação entre a atividade da gestão e a gestão da atividade, instalar dispositivos que permitam a circulação da palavra, co-responsabilidade, aumentando o grau de autonomia dos trabalhadores nos processos de pensar-fazer seu trabalho, aumentar o grau de abertura aos processos de criação implica sustentar a indissociabilidade entre atenção e gestão (Brasil, 2004). Assim, formular propostas de trabalho que afirmem essa inventividade dos trabalhadores, sua potência de renormalização, sem cair nos relativismos irresponsáveis, é afirmar o trabalhador ético da saúde. Essa direção ético-política diz de uma escolha que está relacionada com uma concepção de humano, da qual Cecílio partilha, como um ser em movimento, capaz de imprimir algo de seu naquilo de que participa, capaz de intervir em sua própria história com uma concepção de trabalho como um processo coletivo e singular de criação e recriação da história de um ofício. Talvez esta possa ser uma via para lutar contra o trabalhador funcional/moral que se tem imposto.

\section{Referências}

BARROS, M.E.B.; BENEVIDES DE BARROS, R. Da dor ao prazer no trabalho. In: BARROS, M.E.B.; SANTOS, S.B. (Orgs.). Trabalhador da saúde: muito prazer - protagonismo dos trabalhadores na gestão do trabalho em saúde. Porto Alegre: Unijuí, 2007. p.61-72.

BRASIL. Ministério da Saúde. Documento base da Política Nacional de Humanização. Brasília: Ministério da Saúde, 2004.

CLOT, Y. A função psicológica do trabalho. Petrópolis: Vozes, 2006.

DELEUZE, G. O abecedário de Gilles Deleuze. Disponível em: <http://www.oestrangeiro.net/ index.php?option=com_content\&task=view\&id=67\&ltemid=51>. Acesso em: 12 maio 2006.

Diferença e repetição. Lisboa: Relógio D'Água, 2000.

ROLNIK, S. À sombra da cidadania: alteridade, homem da ética e reinvenção da democracia. In: MAGALHÃES, M.C.R. (Org.). Na sombra da cidade. São Paulo: Escuta, 1995. p. 141-70.

SCHWARTZ, Y. Travail \& ergologie: entretiens sur l'activité humaine. Toulouse: Octarès Editions, 2003. 